OMEGA, Vol. 50(2) 103-129, 2004-2005

\title{
LONG TERM BEREAVEMENT PROCESSES OF OLDER PARENTS: THE THREE PHASES OF GRIEF
}

\author{
RUTH MALKINSON \\ LIORA BAR-TUR
}

Tel Aviv University, Israel

\begin{abstract}
This study is based upon personal interviews with 47 elderly bereaved parents. These interviews provided us with detailed and extensive information on the bereavement processes that parents experience over a long period of years. From an in-depth content analysis of the interviews and the way the parents described bereavement, it seems that it is a central motif in their lives affecting their relationships with each other, with the living children, with friends, at work and with others. Although enduring grief along the life cycle is an un-patterned process with emotional and cognitive ups and downs, involving a continuous search for a meaning to life, we observed a development in this process throughout the years. As we proposed in a previous study (Malkinson \& Bar-Tur, 2000) there are three main identifiable phases in the bereavement process: the immediate, acute phase; grief through the years until aging; and bereavement in old age. We propose to refer to them as the three main phases in the development of parental grieving process and name them "young grief," "mature grief," and "aging grief."
\end{abstract}

\section{INTRODUCTION}

This article follows our previous pilot study (Malkinson \& Bar-Tur,1999) on the "aging of grief," a term proposed by an elderly bereaved father that we adopted

*This article was supported by a grant from Keren Schol and Harzag Institute. 
to describe the centrality of grief in the lives of aging bereaved parents. The themes emerged in a group discussion with 29 elderly bereaved parents whose sons were killed during military service, which suggested that a strong attachment continues in the inner representations of the lost child. Further research was carried out to examine related issues of the process of grief along the life span and in old age. Forty-seven elderly parents were interviewed individually in depth. They were asked to describe their lives following the death of their child until the present. We focus on several issues:

- What are the personal, spousal, family, and social processes reported by the parents as experienced from the moment of notification of their child's death?

- How do grief processes evolve throughout the life span?

- What is the impact of normative developmental processes and losses on their grief processes?

\section{Parental Grief}

The death of a child of any age is traumatic; a profound, difficult, and painful experience. While bereavement is stressful whenever it occurs, studies continue to provide evidence that the greatest stress, and often the most enduring one, occurs for parents who experience the death of a child (Edelstein, 1984; Rando, 1983, 1993; Rubin, 1999; Rubin \& Malkinson, 2001).

The process of conceiving, giving birth, and raising offspring is shared by virtually all living animals. The human experience of this process, however, adds many elements of psychological, social, and meaning construction. At various stages in the life cycle, men and women relate to child-conceiving and childrearing roles as central to their existence. Of the bonds formed within the family, the parent-child bond is not only particularly strong, but is also integral to the identity of many parents and children. Much has been written about the significance of the parent-child attachment bond as a major organizer of the individual parent's positive sense of self and significant relationships with others (Rosen, 1985). Children also assume great symbolic importance in terms of parental generativity and hopes for the future (Christ, Bonano, Malkinson, \& Rubin, 2003; Neidig \& Dalgas-Pelish, 1991; Rosenblatt, 2000). All parents have dreams about their children's future, and when a child dies the dreams may die too. This death of future seems integral to the intensity of many parental responses. Three central themes in the parental experience when a child dies include: 1) the loss of a sense of personal competence and power; 2) the loss of a part of the self; and 3) the loss of a valued other person whose unique character was part of the family system. While guilt and self-blame are common in bereavement, they are especially pronounced following the death of a child. The parental role competence as caregiver, protector, and mentor for their child is severely threatened by untimely death. 
Parents assert that their grief continues throughout their lives, often saying "It gets different, it doesn't get better." Words such as "closure" can be deeply offensive. The few studies that have followed parents for years after the child's death support the concept of their preoccupation with the loss of children across the life cycle (Rubin, 1990, 1999). Klass and associates (1996) refer to the "amputation metaphor": the vivid sense of a permanent loss of a part of oneself that may be adapted to but will not grow back (Christ et al., 2003; Rubin \& Malkinson, 2001).

Aging parents who have lost children earlier in life continue to deal with the meaning of these losses, and continue to be affected even as they age (Rubin, 1990, 1999).

In our previous pilot study of elderly war-bereaved parents who had lost children as long as 33 years, we found that in addition to the losses often associated with aging that parents described, many also described continued difficulties in coming to terms with the loss of the child. Poignantly, a number expressed their fear that the deceased sons would "die forever" when they themselves died. The actual death of the son awaits the second symbolic death - the loss of the child's inner representation which would occur with the death of the parents themselves.

Older bereaved parents also tended to re-evaluate their grief as experienced shortly after the death and years and decades later (Malkinson \& Bar-Tur, 1999, 2000). A central theme dealt with the marital relationship and the relationship with the surviving children. In retrospect, a number bemoaned their intense emotional involvement with the deceased son rather than with the living children. They realized how difficult their grieving and response to loss had been for the other members of the family. Many felt that the continued emotional involvement with the lost son had gone on disproportionately and had affected their ability to fully engage with their families, which themselves were developing and changing. Responsibility to the deceased child coexisted alongside that to the surviving children, even though the parents expressed greater guilt toward them. These bereaved parents seemed to live in two separate worlds - the real and the virtual. In aging, the deceased child is perceived as the more accessible and the more "real" of the children. As one parent put it, "Our children have left home. We are at home with him (the deceased child), he is here with us" (Malkinson \& Bar-Tur, 1999).

\section{Grief in the Family}

Although grief is an intra-personal process involving an inner relationship with a deceased child, it exists within a context of relationships with living family members. Concurrently, grief is both an intra- and inter-relationship. Family members experience grief in an individual, unique way affected by the special interactions, intimacy, and history that they shared with the deceased. 
Seeing that the grief process within the family has so many facades and layers, it is not surprising that a variety of experiences and reactions to grief are reported.

Some families report that the experience brought them closer, some describe considerable distance following the loss and even a breakdown within the family (DeFrain, 1991; Riches \& Dawson, 2000; Schwab, 1996).

It has been assumed that the death of a child may have a negative effect on the marital relationship, increasing the likelihood of divorce, but this assumption was not supported empirically. Schwab (1998) argues that marital distress and communication problems should not be equated with marital breakdown. Bereaved parents might feel considerable distance and irritation with one another for some time before regaining the same or even greater level of intimacy than they shared before the child died.

Parents and siblings seem to grieve differently. Differences may be related to the developmental stage of the bereaved (adults and children), the role each one has in the family, as well as gender, cultural, and personality differences (Martin \& Doka, 2000).

The majority of published findings indicate that fathers, at least in the initial phase of bereavement, are more likely to put their energies into practical issuesin supporting their partners and controlling their own emotions - to rationalize the loss in terms of its wider implications for the family and to find ways of diverting their grief into practical activities. Mothers, on the other hand, are more likely to connect directly to their raw feelings, responding to the death through the experience and expression of strong emotion (Conway \& Feeney, 1997; Kavanaugh, 1997; Levav, 1989-1990; Riches \& Dawson, 2000).

It is accepted that the mother's role is generally far closer to the child, not only emotionally but also practically. This may explain the gender differences in strength and duration of grief. We should also take into account cultural roles and expectations which explain the different reactions of mothers-women and fathersmen (Lang \& Gottlieb, 1993; Lesher \& Beyer, 1988; Martin \& Doka, 2000).

The death of a sibling, at whatever age it occurs, can have far reaching effects on the individual. The age of the child, his personality, and the circumstances of the death will interact to determine a child's reaction to the loss of a sibling (Cicirelli, 1995 ). Another important issue in understanding children's grief is related to the fact that in bereaved families the parental grief is the focus of attention. This is often experienced by children as a "double loss": that of the sibling and of their parents. Studies on bereaved siblings are relatively new and reveal the children's vulnerability, difficulties in functioning, social isolation and more, mostly during the initial phase of bereavement (Christ et al., 2003; Davis, 1999).

We describe here the diversity and complexity of grief reactions in the family. In this article we focus on these reactions from a life-span perspective as perceived by the parents. 


\section{RESEARCH METHODS}

\section{Collecting Data}

The interviewees for the study were selected from a registry of names of bereaved parents which was given to us by the Yad La-Banim organization ("A Memorial for the Children," a national organization founded by bereaved parents for parents who lost their children during military service). Personal letters were sent out asking parents over 60 years of age and residing in the central region of the country to participate in the study. A total of 130 letters were sent out. In addition to these letters, a notice was placed in the quarterly publication published by the Yad La-Banim organization, describing the study and requesting people to participate.

Some of the letters returned, apparently because the addressees had moved or died. A total of 64 people responded and wanted to be interviewed. Some of these were not included in the study (for example, because they were parents of handicapped soldiers, or parents who expected to receive help concerning financial or other problems).

The interviewed parents were those who had replied affirmatively to our requests and expressed their basic agreement to be interviewed. During preliminary telephone conversations between the researchers and the parents, the parents received detailed explanations regarding the objectives of the study and the issues to be covered and discussed during the personal interview. In addition, an explanatory letter was sent.

The study was based on a semi-structured personal interview conducted by experienced social workers. The questions focused upon issues that were relevant to the grieving and aging process, as culled from findings included in the pilot study and from reading relevant literature. The issues related to the process of life from the time the child had passed away until the present, to the way contact with the deceased child continued in the internal and external world, to possible changes occurring that are related to old age, to the way in which the pattern of contact with the deceased child is formed at this stage in life. We touched upon the effect of bereavement upon the spousal relationship, relationships within the family, professional and social relationships, as well as changes which occurred in each of these domains.

The interviews took place in the interviewees' homes, at hours which were convenient for them. The decision to interview a parent in his or her home was made to obtain a sense of the interviewee's environment and to acquire additional information regarding the home atmosphere, to find various signs and other demonstrations of the deceased child's presence and of the bereavement, all within their natural surroundings.

Interviews lasted an average of two hours and were recorded. The transcripts were typed up. Great care was given to transmitting nonverbal expressions, such as long silences, signs, etc. 
At the end of the interview, parents were given the opportunity to contact the interviewers, should they desire to do so.

We were contacted several times after the interviews. Two letters of thanks were received from parents for whom this had been the first time that they had been able to fully and personally share their story, as well as a request from a bereaved parent who wanted to continue personal contact with the researchers, which resulted in a meeting between the two researchers and the parent.

\section{Characteristics of the Participants}

Forty-seven bereaved parents who lost their sons in war or during military service were interviewed for the study, 22 of which were fathers and 25 mothers. The average age was 75 , the youngest being 61 and the eldest 92 . Thirty-seven were married, of which 30 both husbands and wives were interviewed. Eight were widowed and two were divorced.

Sixty-six percent of the parents were retired, $17 \%$ had part time jobs, and $8.5 \%$ were working full time. Among the bereaved interviewed, $45 \%$ had 13 or more years of education, $46 \%$ had high school education, and $9 \%$ had elementary education.

Sixty-two percent identified themselves as secular, $28 \%$ were observing religion, and $2 \%$ were very religious (as some data are missing, this is an approximate value). Health status ranged as follows: $49 \%$ reported average health status, $37 \%$ reported good health to very good health, $15 \%$ reported bad health. The period of bereavement ranged from 26 to 35 years. The range of the dead son's age was 19-30 years. Out of the 47 parents, two had no other children, five had only one child, 19 had two children, 13 had three, and eight had four other children.

Twenty-three parents reported having experienced additional losses since the child had died (parents, siblings, other significant persons); 13 parents were Holocaust survivors.

\section{Analysis of the Interviews}

Content analysis of the interviews was carried out in accordance with the accepted criteria for analyzing content (Patton, 1980). The analysis was based upon three principal stages: 1 ) inclusive understanding of the substance of the interview; 2) separating the content of the interview into significant units; and 3 ) thematic analysis of the various themes (significant units).

At first, each interview was read thoroughly in order to obtain a comprehensive first impression of the atmosphere and the interviewee's personal story. The initial feeling of the interviewees was one of great emotional intensity, regardless of how many years had passed since the loss. Many expressions of pain and sadness which were undiminished with the passage of years came to the forefront. The tragedy - that same "earthshaking" feeling that was felt following the child's 
death, the interrupted story, life before, life after-was a prominent part of the stories.

During the second stage, the interviews were analyzed in keeping with the character of the units of significance. During this stage, each interview was once again read very carefully and the themes, as well as other conspicuous elements which repeated themselves throughout the interviews, were noted. At this stage, various comments were made regarding the topics that came up.

After the initial analysis of each interview, all of the themes were listed. These became the categories of the first analysis. We established a list of groupings which dealt with continued contact with the deceased child, the interrelationship between the parents since the loss of the child, their relationship with other members of the family, their contact with institutions, commemorating the deceased child, old age, other losses, etc.

During the third stage of the research, after the initial subdivision into main categories, we found that some categories had sub-categories, and thus new categories were designated. For example, during the personal grieving process, sub-categories relating to different expressions of a continuation of contact with the deceased child stood out, particularly in the form of emotional, cognitive, behavioral, and somatic expressions. The division into sub-categories was done by four referees who read and analyzed a number of interviews before determining the sub-categories.

At the input stage, a list of criteria, or groupings, which either described or dealt with the particular contents of each category or sub-category was determined for each category. That is, acceptance conditions were determined for each category. The nuclear categories reflected the central themes of the interviews, and from these each of the other categories is derived.

After reviewing all the categories, and after repeatedly comparing and contrasting the categories and patterns which arose as well as attempting to link categories through causal or other connections, the researchers came up with three nuclear categories and 20 sub-categories.

During the next stage, these categories were grouped under separate computer files which contained relevant quotes from the interviews as well as comments made by the researchers. All of the themes were organized into an integrated and coherent story that examined the reciprocal relations between them. The researchers discussed other implications that arose from the hidden and manifest contents which are part of each of the theme file as well as possible links between the central categories. After processing and analyzing the categories repeatedly, an initial model was formulated for presenting the data, reflecting the main issues that arose during the interviews. Another division was made according to a timeline that illustrated the periods immediately following the loss, over the years, at the present time - the aging process.

The final model contained an analysis of the nuclear categories from the aspect of a dimension of time. 


\section{Findings}

The findings of the study point to the focal magnitude of grief in the parental world through the years. The main themes in their life revolve around idiosyncratic personal contact with the deceased child, the relationship between the spouses, with their other children, with society, the importance of work in their lives, and the manner in which they perceive the significance of the loss and their own lives over the years.

The various domains of life revolve around a central theme that is the continuation of the relationship with the deceased child after the loss. We discerned two main levels in this theme: the first level is the interaction between the parent and the deceased child on an inner, personal level, and the second one is the interaction between the parent and the deceased child on an interpersonal and social level.

The parental descriptions of their way of life since the death of their child point to an evolution in the grieving process in all domains, particularly that of time. From the time-line perspective, it is possible to identify them as three main phases of the various expressions of bereavement. The first phase is acute grief; the second relates to bereavement over the years, and the third, grief in old age.

We shall focus on the three phases as they emerged during the interviews, referring to emotional, cognitive, and somatic behavioral expressions of personal grief and bereavement in the context of interpersonal-family connection.

\section{THE PERSONAL BEREAVEMENT PROCESS- THE CONNECTION WITH THE DECEASED CHILD ON THE INNER-PERSONAL LEVEL}

\section{Acute Grief}

When reconstructing the initial phase of this traumatic bereavement, older parents describe strong and powerful emotions of pain and loss. In re-experiencing the acute phase of the loss, these reactions were mainly shock, sorrow, anger, tears, a feeling of guilt, a feeling of loss, and missing something. The gamut of reactions expressed through the parents' activity and behavior ranges from hyperactivity with an attempt to escape to withdrawing into oneself and hypo-activity. A common reaction at this stage is copious crying, or escaping from the house, unease and restlessness, becoming addicted to work, frequent visits to the cemetery, or conversely, becoming a recluse and withdrawing into oneself, having difficulties with talking or crying.

Based upon the perspective of the passing years, most parents did not find it difficult to reconstruct the details that occurred on receiving notification of the son's death. Quite to the contrary-the impression was that they were not hesitant about inviting us to be participating listeners to the details of the story. Indeed, most of the descriptions were given in minute detail and were very real. 
When the stories were told in the present tense, the description of an event that took place in the distant past was accompanied with turbulent feelings, despite the fact that it was told and reconstructed many years later.

I shiver and tremble as if it is happening now ... my husband began shouting and screaming. Me too. A doctor stuffed a pill in my mouth. I trembled. I cried. Look, I'm trembling now. . . .

We found that the various characteristics of expressions of grief in the bereaved parents' descriptions substantiated all of the various stages and psychophysiological elements anticipated during its progress.

We found out that parents' description of the acute phase included a wide range of reactions, differing between parents.

From the moment of notification of the child's death, various expressions were identified relating to difficulties to act as if life goes on normally. Two patterns are prominent in each characteristic: the first is externalized and very powerful, while the second is introverted and restrained.

Most of the reports regarding somatic reaction occur at the onset of the grief when notification was received, but some continue along the life span, as can be seen by the statement of one of the mothers:

This pain becomes physical. Sometimes you feel a pinch here. That something is happening here, you become short of breath, and the emotions become physiological. ...

One common, very powerful expression of emotion is persistent crying. On the other hand, at the other extreme, there is emotional control and a refusal to cry.

A prominent and additional dichotomous trait is the behavioral expression of grief, such as hyperactivity, burying oneself in work or in activities at home:

During the first six months, I wasn't completely there at work. I couldn't concentrate. I would work until 10:00 o'clock at night every day, just to keep myself busy, I only wanted to work and keep working, just so I would not have to be at home.

Hyperactivity was also expressed in attempts to preserve the relationship with the deceased; for example, by making frequent visits to the cemetery.

In addition, hyperactivity is also expressed by a return to normal activities, which seemingly contradicts the grieving process.

However, some described a pattern of under-achievement, of becoming introverted, falling into a kind of catatonic numbness:

I was on the edge of an abyss.

Some described preoccupation with the deceased as an inner-personal, private meeting, characterized in words, written, documented: 
I opened a new leaf in my relationship with him, I would tell him everything that happened to me, I would tell him everything, how I felt, what was happening on the kibbutz. ...

The main characteristic of cognitive expressions is constant preoccupation with thoughts that turn around the child. In time, thoughts take on different expressions. In the beginning, there is a diffuse type of thinking, characterized by the knowledge that this has happened and the difficulty in accepting it. Later on, thoughts about the child become part of the routine, a surrogate for actual verbal contact.

\section{The Grieving Process throughout the Years}

In contrast with acute grief, sorrow that persists over many years becomes, according to the parents' narrative, interwoven in their lives and grows to be an integral part of their repertoire. Contrary to acute sorrow, which is described as an external event that has occurred - a disaster, an earthquake, where a person finds that they are helpless, where the event has not been internalized, where the person is incapable of controlling the functional and the emotional world-years later, some of these emotions remain valid. However, emotional reactions become more familiar, less intense, part of the reaction repertoire that is known in advance, and there is a kind of resignation that the pattern of grief has become part of life:

One can get used to it, but one can't get over it. - Ido's mother

Nevertheless, the pain, as described by some parents, was unremitting and profound:

Since Meir was killed, the same pain pervades the home. It does not diminish.

The pain, the sorrow and the loss are an integral part of the life of the adults and the aging parents.

\footnotetext{
It is as if you had lost a hand and had become a cripple. In the beginning, it hurts a lot, and one doesn't know how to manage without the hand. Later, it forms a scab and is bothersome, and then, you are fitted for a prosthesis and you begin functioning. And the prosthesis is so good that no one realizes that you are missing a hand. But in the evening, you remove the prosthesis and you are left with a void.
}

The ability to contain the grief reduces the need for the grieving parents to run away from the house, from themselves, from their family, toward work, to hyperactivity, as some of the parents described their experiences during the initial stages. There appears a certain amount of moderation, a certain calm, the pain becomes more subtle, less sharp, but it is a constant in their lives, it is ever present: 
It doesn't change over the years, it is different. I speak and I become excited, it is different today; I don't run to the cemetery every day. Not even every week, but it is something that never ends.

All this transpires in conjunction with the central presence of the deceased child within their private world.

He is always here, as if he had never left. Sometimes, I have him. I think of what he would have said about this. I don't think of him in a crazy manner . . we still see him as a child.

And the feeling of loss is strong:

I would so much like to hear his opinion and consult [him] and make contact somehow.

\section{Sorrow in Old Age}

At such a young age, as long as we don't comprehend the extent of the tragedy, it is a kind of play. You know, a play, and the curtain comes down ... it is hard. Now, as one grows older and older, there is no . . it is impossible, it is hard to describe . . . because we become mad, start the car, go to the cemetery. This is coming to our senses. And I say that the difference between the young and the old is maybe in the beginning. Only in the beginning. But after that, there's no difference.

The link between bereavement and aging, as becomes evident from descriptions provided by parents, is complex and yet it fluctuates from parent to parent:

Sorrow has an effect upon old age, just like everything else. It leaves its mark, that's for sure. And it's different for each person. No two people are the same.

Everyone has fears, and at this age, many are alone. And it is truly terrible, there are thoughts, this certainly occupies [one's mind].

Despite the diverse reactions, it seems from the narratives, that bereavement is being more burdensome in old age. The aging process involves other significant losses, such as parents who become ill and die, losing one's network and employment, friends, spouse, one's health, and the house becomes empty. These losses and changes have an effect upon the bereavement pattern during old age:

Compared to the past, today I feel that there are no parents, no work, we have lost many friends, then suddenly, ah . . . it's not as if I didn't know from the beginning that the difficulty is that there is no hope, no continuity, yes, I knew, but I had the family's support and also had to take care of them. This doesn't exist anymore, these compartments became empty as soon as they died.

Parents have more empty periods during the day, and they fill them with thoughts and memories of their deceased child. The outside world shrinks and the inner world in which the deceased child exists expands. The house is empty of 
growing children, however, the memories of the deceased child are left behindphotographs, belongings, souvenirs; all these continue to exist. It seems that the deceased child's position becomes more and more crucial as the other children leave the house:

And suddenly we see who will help, he is no longer here, it is hard, so everything is hard. And it is even harder to bear it, when old age comes, everything shrinks, the circle of friends shrinks, and a person calculates, the children will help, and the sorrow and bereavement remain with us and I see his photograph, I begin crying, it is very difficult.

In addition, the feeling of having missed out on what could have been had the child remained alive, grows increasingly during the aging process:

Every thought - if he were [here] it would certainly be different, and me, if I think logically, I'm not sure, but this thought, these daughters are really great, but if something somehow touches us, if Gadi were alive, it would be different, you see, and there is no arguing with that.

In spite of the fact that the body is growing older, and that the aged parent's appearance has become heavier and more passive, there is something constantly active on inside. There is an intensive inner life. There is constant interaction with the deceased child; they speak to him, consult him, ask him questions, keep him posted about what is going on. This gives the parents strength:

He has not been erased [from our lives], he is with me every day, every hour. Not just in my thoughts. I talk to him. His photograph is here, always besides me. He lives with me. And the relationship with the grandchildren and the great-grandchildren - these take me back anew.

At one level, there are memories from the past, and at the second level, it is as if he has grown up with them and accompanies them all the time:

He accompanies me every day, every hour, he is not erased.

Ziv has more influence than a living person.

This has an effect on the significance of the present life. There is no watch and time does not exist. The space the child occupies expands constantly. He grew when the other children left the house. The parents are left with the deceased child. Unlike other types of grief, where the space is preserved but remains small and makes room for other kinds of relationships (a spouse):

I am even more moved today, tears fall involuntarily.

Ran's death hurts today exactly as it hurt then.

Along with the loss of significant people during the aging process, such as parents, siblings, friends, etc., many of the bereaved parents undergo renewal processes - for example, in the form of their grandchildren. Family occasions and 
the development of the younger members of the family can fill that great void, but only partially, and only to a limited extent:

The grandchildren are a great comfort, when we are with them, we forget for a few hours....

From the bereaved parent's point of view, the role of being a grandparent is probably more complex and broader, because this means that he/she must also, once again, become a parent (a kind of reconstruction of the lost role of parenthood).

He said to me (the grandchild) - grandpa, you can be my father. I felt how much he wants his father.

However, there are some who find it difficult to let the grandchildren in on an emotional level:

I don't have the patience for grandchildren. I love them and my sons. They come. I prepare everything that has to be prepared, but there is no true enjoyment or joy.

We can see that in old age pain does not diminish but continues to be a significant and profound component of daily life. However, there are many ways to experience it as expressed by the parents' diverse voices.

\section{THE IMPLICATIONS OF THE GRIEVING PROCESS ON SPOUSAL AND PARENTAL RELATIONSHIPS}

A death in the family is a multi-dimensional crisis situation with dual potential: it either brings family members closer together or creates a distance between them, and sometimes, even brings about a breakdown in the relationship.

The death of a child had a very disturbing effect upon some couples. The spousal relationship was destroyed and bereavement became the focal point of their existence. Nevertheless, in spite of the difficulties, most couples were able to deal with the loss. There were also some who claimed that their relationship was not particularly affected by the loss.

Those who spoke of the severe effect that the death of their child had upon their relationship described a collapse or distancing that resulted from one of them being very hard-hit by the notification of the child's death. Some of the parents described a feeling of alienation or strangeness that was produced as a result of the different ways in which one member of the couple expressed his/her grief, and by a difficulty to share that grief:

Each one kept it inside. We did not discuss this with each other.

Each one of us grieved in a different fashion, I sat in my corner and licked my wounds, I could sit on the balcony the whole night and simply weep, 
and my husband needed to talk to people, and this clashed. I felt alone, so very alone....

In contrast, some described much mutual support:

She broke down completely, she was totally out of it. . . I try to support her, as a man, I am somewhat stronger, despite the fact that I sometimes put on an act.

Dina had to hold me up, to calm me down, to help me to sit down and I drew a lot of strength from her.

There were also those who were drawn together by the loss, where the loss gave them a chance to open up to one another:

We remained the same together, one with the other, one being there for the other, but with a heavy pain in our hearts.

This brought us closer, we have a common language.

Therefore, it appears that the sudden death of a son in a war or during military action affects the spousal relationship but that the effect is multi-directional, not necessarily that of alienation, as is customarily thought. Reactions to bereavement are different and unique for each parent. With the passage of time, as they get older, the couple tends to drift toward openness and a growing feeling of closeness, a tendency that can be attributed to the evolution of the bereavement process.

What has changed is a general sense of coming to terms, we were always on different planes. Slowly, with the passage of time, we understand that we cannot change [each other] and he lives his life, and I live mine.

We walk holding hands. When we began getting over the harsh blow, after a certain period of time, since then, we walk holding hands with this grief. ...

\section{The Bereavement Process of the Parent and} Its Effects on the Relationship with the Other Children

In the course of the present study, we found parents who, in addition to their own suffering, expressed their awareness of the fact that their children were suffering, and some reported their inability to make time for the needs of the other children because of the force of their own personal grief. This led to a complicated relationship in these families, a relationship which, in some cases, has lasted until the present day.

There is also a process that develops over the years in the parents' relationship with the other children. As in reports from other studies, we found that during the initial stage of bereavement, the relationship with the deceased child occupies a central role that is often at the expense of their relationship with the living children: 
Most people make the same mistake, that they are so immersed in their grief that they forget that there are other children. ... We had three other children and we neglected them . . . they were small and we left them, we simply did not have the patience for this . . . each person overcomes his problems in his own way, by himself.

Another and seemingly different expression of the way in which parents deal with bereavement and its implications on the living children is by worrying too much and being overprotective of the remaining children. There were parents who described their attempts to protect their children from everything:

After Amit's death, I took care of Dana more than was necessary, I was constantly after her, I watched over her like a hawk. I was afraid for every step she took, more than before. I was so afraid for her, I paid so much more attention to her. I really lived in fear. I was always around her.

This same over-protectiveness, like the withdrawal into oneself and the unavailability described by other parents, is in fact the result of the great emotional distress experienced by the parent during the stage of acute grief. The tendency toward over-protectiveness and increased worrying express the parent's increased preoccupation with the deceased child, conveyed by their growing fears regarding the safety of the living children.

An additional expression of grief described by the parents is the attempt to hide or isolate their grief from the children. However, this did not resolve the load and the feeling of the responsibility carried by the children.

Over the years, parents are able to look back on themselves as parents and scrutinize their ability to give the other children more leeway and recognize their needs then and now. This realization, as described by the parents, enables the children to express their needs today. In looking back, the parents are able to understand that the loss of a child affected each and every member of the family separately and in a different way, in addition to the family's grief as a system.

The problem lies more in the brothers and sisters that remain behind, it is very important that this be emphasized, they suffer very much and they cannot show how hard it is for them.

Nevertheless, in some families, the role of the remaining children is considered to be an element that spurred them on, to continue their daily routine, to hold the family together. In other words, the role of the children is to bind the parents to living.

If Dana were not in the picture, I wouldn't care at all.

It was [the fact that there was] another child in the house that helped us cope and recover. There was something to continue living for.

When old age sets in, the family becomes increasingly important to the old people's lives. It is as if the relationship with the remaining children becomes 
stabilized and strong, particularly after the birth of grandchildren. However, in spite of this, there is no feeling of unity, the deceased child's place remains central and it seems that life is only analyzed from the aspect of the deceased child:

The girls grew up very slowly, went through the army, studies, got married and everything, and then the thoughts started again ... the feeling that it is good but not complete.

\section{DISCUSSION}

This study is based upon personal interviews conducted with aging bereaved parents. In comparison with the group interview presented in the pilot study (Malkinson \& Bar-Tur, 2000), these personal interviews enabled us to acquire detailed and extensive information on the bereavement process that follows a person over many years. This was an opportunity for the bereaved parents to relate their own personal story, guided by a number of deliberately directed questions.

The parents who participated in this study responded willingly to requests to tell their story. In fact, it seemed that they saw this as an opportunity to share their painful experience since, with the passage of years, they felt that the interest of their immediate surroundings in them had abated. Despite the declining interest on the part of their environment, we found that the story continues to be vibrantly alive in their inner world. They continue to be preoccupied by it and whenever given the opportunity, their story bursts out in full force.

The first central issue in this study deals with the question of what processes did the bereaved parents undergo in the various domains of their lives from the moment they received notification of their child's death until the time that the interview took place.

During the interviews, it was evident that the parent's stories followed similar directions in referring to the period as one during which their lives were split into two separate chapters. The first chapter, which was not widely covered in the interviews, relates to their lives up to the point that their child perished. The interviews focused mainly upon the second chapter of their lives. The second chapter begins with the great catastrophe- "the great explosion," "the earthquake" - that takes place when they receive notification of the death of their child.

\section{The Personal Bereavement Process}

The interviews demonstrated that the actual notification of the death of the child, and the powerful emotions accompanying this event, play a central role in the story. From long time perspective, the moment of notification is remembered in minute detail, as if it had happened just yesterday. The sensations of that very moment, of that event, remain very much alive, accompanied, even today, by great emotions and somatic expressions and in many cases, by tears. 
The parents' description of their immediate reaction to the loss is reminiscent of post-traumatic reactions, but it differs in that the re-enactment of the incident and the relating of the smallest details are very important to the grieving process and to accepting the fact that death has occurred. Flooding may occur during the re-enactment but there is no hesitation. While in post-traumatic stress reaction there is a cathartic impact to describing the traumatic moments and focusing on the traumatic event, in traumatic bereavement, with the passage and distance of time, this critical value still helps to clearly preserve the feelings experienced at the onset of the "calamity" in their lives .

Heaven fell all around me, continuity was cut off. My world crumbled around me.

While with post-traumatic stress, flooding or avoidance evolve from the event itself, in most cases of traumatic grief there is no avoidance (in those cases where avoidance is present, it relates to the re-enactment of the announcement of the child's death) and flooding is part of the parent's preoccupation with the deceased child. (Malkinson, Rubin, \& Witztum, 2005; Rubin, Malkinson, \& Witztum, 2003). We think that this kind of flooding plays a central role in keeping the child's memory alive.

After providing a description of the turmoil and devastation they felt with the onset of the grieving period and with the abatement of the storm, the parents continue describing the process of reorganizing their lives and gathering up the broken pieces of their lives after the loss, where the length of time of this stormy period differed greatly from one set of parents to another.

From the parents' description it is clear that despite it all, they begin to collect the broken pieces and their lives "go on." They continue wondering and asking how their lives will now be shaped on every plane. In addition to the pain, the confusion, and the deep sorrow that exist and the void that has been created, there is also a kind of strength that impels them to continue, accompanied by a feeling that is just as strong that life, or a part of life, has come to an end, never to return. The initial period of re-organization is described as consisting of automatic actions rather than as anything else. It is possible to recognize here an attempt to return to one's routine even if internally, the person is still not pulled completely together. The parents are still not able to fully control the emotional and functional world that has become distinguished by extreme reactions ranging from hyperactivity to lethargy.

This is also valid for expressions of grief. As long as the loss has not been internalized, the parent's behavior is a reaction to an external event alongside initial steps that begin to give significance to a loss that is itself part of the parents' initial attempts at reorganizing their lives.

Further, in the study it becomes evident that emotional and physical reactions subside. They become subdued and are affected by the ongoing process of 
meaning construction to life and loss that is based upon ideas, beliefs, and outlooks (Neimeyer, 2001; Neimeyer, Keese, \& Fortner, 2000).

As the years pass, the pain inflicted by the loss and the deep sorrow persist, but they are transformed - they become accompanied by an acceptance of an external reality without the child, but where the child remains part of the parent's inner world. A normal routine takes on shape, where patterns necessary to function in the different spheres of life have become reorganized. Alongside their inner private lives and the loss, the parents occupy themselves with developmental functions that include caring for the living children, working, the extended family, caring for older parents, and social interaction.

Despite the fact that the pain and sorrow do not abate, and in contrast to a traumatic event, it seems that these reactions are not accompanied by a struggle or attempts to dispose of them or to eliminate the fear of their actual existence. Moreover, it seems that older parents consider these complex feelings as a way or an expression of ways to maintain an emotional link with the deceased child. The child is eternally present, a kind of "presence-absence."

The ability to endure grief reduces the need to escape from the house, from themselves, from the family, to go to work, to participate in extreme activities, feelings that some of the parents described as having experienced during the initial stages. There comes a feeling of moderation, a certain sense of tranquility, and the pain becomes gentler, less sharp, duller; but, nevertheless, its presence is constant. However, in aging it seems that the sense of loss is more dominant as the parents' need for support increases while living in an empty house "full of memories" of the deceased child.

\section{The Bereavement Process and Its Implications on the Couple's Relationship}

When examining the implications of grief upon the couple's togetherness through the years, it was discovered that this involved a process similar to that expressed by the parents when describing personal grief; that is, the different stages of the reactions to the death had different effects upon the couple's relationship. Their descriptions placed great emphasis on the initial stage, the stage of acute grief.

Immediate reactions to loss are very intense and very personal, and therefore, during the initial stages, the most common inclination was to isolate oneself from the other and survive. From the way the parents described the personal grief process it seems that some immersed themselves in their work, some shut themselves off from the rest of the world, some cried, and others avoided dealing with the situation openly.

The interviewees described the stage of acute grief as working through difficult feelings in dealing with the situation on a personal level. The same difficulties were described as being present in the relationship between the couple itself, as 
well as with other members of the family. Nevertheless, over the years most couples described a growing closeness, mutual acceptance, and an improvement in their ability to relate to each other and talk about their feelings and the dead child.

We walk holding hands. When we got over this a little bit, after a certain period, we now hold hands with this sorrow. ...

In time, the couple's relationships evolved and made it possible for them to grow closer even when the initial stage of bereavement was the cause for remoteness and detachment. It is important to stress that in the initial acute stage, the grief is naturally personal and intense and cannot be shared with another person, no matter how close that person is. Therefore, the difficulties the couple and the family in general face when dealing with grief are understandable. At that stage, it is not unusual for the couple's own relationship, or its relationship with the rest of the family, to undergo an upheaval. During the interviews, we found that some of the parents had felt a sense of detachment, remoteness, a disparity between their individual reactions to grief and had found it difficult to share the pain during the acute stage. In time, it seemed that as they matured and aged, the couple found it possible to accept the dissimilarity between their different reactions to grief. They found that they had grown closer and were even able to share feelings and thoughts about the child.

This phase in the older parents' relationship can be understood also as their emotional development. In older marriages there is usually more harmony and less polarization between mothers and fathers in their grief reactions (Martin \& Doka, 2000). The resolution of conflicts is less negatively emotional and more affectionate than in middle-aged marriages (Carstensen, Levenson, \& Gottman, 1995).

\section{The Bereavement Process and Its Implication on the Parental Relationship with Other Children in the Family}

As stated above, the death of a child greatly disrupts the life of the whole family and also affects the relationship between the parents and the other children. In addition to their own personal grief over the loss of a brother or a sister, the siblings find themselves having to deal with their parents increased preoccupation with the deceased child, which detracts their attention from the living children. The parental bereavement is expressed by great feelings of pressure in the various spheres of life and their inability to function. The consequence of this reality and the attendant difficulties is that, as a result of the child's death, they now have to deal with new obligations and duties in their daily lives. The siblings, therefore, have not only lost a sister or a brother, but also a significant part of their parents.

During this study, we found that parents recognized and even gave expression to their awareness of their children's suffering in addition to their own. There were 
some who explained their inability to take care of the needs of their other children by the fact that they had been so immersed in their own grief. In these families, this gave rise to complicated relationships that in some cases are still unresolved today.

The parents' description of their relationships with their other children once again points to a process that evolved over the years. During the initial period of bereavement, we found, as in previous studies, that the relationship with the deceased child played a major role in the lives of the bereaved parents, often at the expense of the children who were still living. In retrospect, and with a certain feeling of guilt, some parents describe the difficulties they had investing in their other children. They expressed the feeling that they had neglected them. On the other hand, other parents still feel the consequences of this emotional neglect - the children's anger, the lack of a relationship between the parents and the children, accusations heaped upon them by their children, etc. Some parents overcompensated by being overprotective and worrying too much about their other children, particularly in cases where the parents were motivated by fear and their own needs and were not focused enough upon or attentive enough to the needs of their other children. Even those parents who tried to hide their grief from the children were not able to prevent anguish from permeating the atmosphere in the house. It seems that this bereavement process, just like that undergone by the individual and the couple, is inevitable during the initial difficult stages of parental bereavement.

As years pass, when the parents come to accept and tolerate reality without the presence of the child and are able to gradually develop a new routine, the parents are once again able to invest in their other children.

Most people make the same mistake - they are so immersed in their sorrow that they forget that they have other children ... we had three other children and we neglected them . . . they were small and we deserted them, we simply had no patience for that ... each one overcame his own problems in his own way.

During the aging process, the parents describe the growing importance of a relationship with children and grandchildren, but at the same time, there is no feeling of wholeness. The deceased child's place continues to be the center of their existence and life is not only observed in terms of what it holds, but also in terms of what is missing, expressed by feelings of having missed out on something, feelings which continue to be part of the parent's life, feelings which become stronger as the parent becomes older, in the sense of "if Gadi were alive ... then...."

The conclusion that can be drawn from parental statements is that despite the fact that, throughout the years, they were preoccupied with grief and the unfathomable pain felt over the death of their child, in retrospect, after many years, they have become more aware of the "double" loss suffered by their surviving children, even if, in practice, they cannot change the past. 
Slowly, the girls grew up, finished the army and studies and get [sic] married and everything, and once again the thoughts arose . . . the feeling that it's good, but not complete.

Ziv has greater impact than a living person.

\section{Parental Bereavement as an Evolutionary Process}

From the description given by elderly bereaved parents of their lives from the moment they receive notification of the death of their child, it seems that there are evolutionary processes in all of the domains which we touched upon. The first studies in the field of parental bereavement focused upon grief during the initial phases, and continued for a few years after the loss, during which the patterns for living without the deceased child were formed. Lately, the tendency has been to examine grief as a normative and continuing process that lasts a lifetime. (Klass et al., 1996; Riches \& Dawson, 2000; Rubin, 1992, 1999, 2000; Rubin \& Malkinson, 2001).

The present study supports those findings and shows how the bereavement processes continue in full force during aging. From an in-depth content analysis of the interviews, it seems that parents' narrative of their long life loss evolves and develops, with grief continuing to be a central motif in their lives. We proposed (Malkinson \& Bar-Tur, 2000) to refer to this developmental process as consisting of three main phases: the immediate, acute phase; grief through the years until aging; and bereavement in old age.

Acute grief can be treated as "young grief" in that it is stormy, agitated, less focused. At this early stage there is some sort of collapse, a disintegration accompanied by intense reactions of grief and trauma and the shock and flooding of deep pain that permeate all spheres of life. The grief is also young because of the resultant confusion, the difficulties involved in reorganizing one's life as a result of this incomprehensible disaster which has befallen the parent. During this phase, parents withdraw into themselves, each trying to survive and to grasp the significance of the loss. During the stage of "young grief," the person is unable to internalize the loss and therefore feels out of control and seeks a way to survive.

With the passage of time, one can see the beginning of a movement in the direction of more "mature" grief. In contrast to acute grief, in time grief becomes interwoven in the parents' lives and becomes an integral part of the fabric of their lives. If during the period of young grief, their ability to control their functional and emotional world was limited, during mature grief, feelings remain valid but the emotional reactions are more familiar, less intense, and have become part of the repertoire of reactions which are known in advance and anticipated. The existence of a pattern of bereavement which has become part of life is accepted. As can be seen from the parental description, one now accepts the deep pain and sorrow of the loss without attempting to flee from it and one is no longer afraid of 
the very fact that it exists, as was the case during the initial phases. The ability to contain grief makes it possible for the parents to grow closer, the tendency to flee the house lessens and one becomes more capable of developing an attitude which acknowledges that there are different ways of accepting and reacting to loss. During those years, each parent also undergoes a personal development, which finds expression in their mental and emotional investment in life, by involving themselves in a variety of occupations and activities that give significance to life despite the loss. Another meaning to the continuation of life is made possible through commemoration, which molds and establishes itself in their lives. A routine is created where there is a legitimate place for keeping the child's memory alive.

It seems that this development in the grief process relates also to the emotional maturation in middle age and in aging. Maturation of the parents' defense mechanism and their coping strategies is reflected in their mastery of feelings and the ability to better contain and control their never-ending pain and sorrow (Diehl, Coyle, \& Labouvie-Vief, 1996; Valliant, 2002).

The third phase relates to bereavement during old age, or as we proposed to call it (Malkinson \& Bar-Tur, 1999), "aging grief." It seems that a major feature of aging is a continuous preoccupation with representations of the lost child. Sorrow continues to be the central axis in the parents' life, separated from the developing processes. Other normative events (such as children's weddings, retirement, becoming grandparents, changes in one's medical condition, and becoming widowed), continue to take place despite the fact that grief is a constant in their lives. The important goal after a loss was and remains how to maintain a continuous relationship with the child who is no longer alive. In fact, after the child's death, the parent's internal life remains interwoven with the child alongside their existence as part of an external world in which he or she no longer exists.

The parents' adaptation and coping in aging can be explained according to Lomranz (1998) as aintegration. Aintegration is the ability to feel integrity without necessarily having integrated everything. It is the ability of the older parent to feel well despite continuous pain and sense of loss. It entails a possible sense of inconsistencies, discontinuity and even absurdity. The ability to bear emotions, thoughts, and behaviors which may be inconsistent, enables them to feel good and bad, have tears of love and sadness when significant events occur in their lives and that of their children (graduations, weddings, birth of grandchildren).

Aging increases the aged parent's need for dependency - the need to consult, lean on, and receive help from the children. This situation increases the feeling of loss regarding the unrealized potential of the child as a caregiver for an aging parent, had he or she been alive. The feeling of having missed out on something increases. The feeling of having missed out on something, however, is not only valid in regard to the past but grows with the years and is always directed 
toward the future. This feeling increases with the need of the aging parents to find safe harbor in their children, a secure base, as Bowlby (1980) described it, or, as expressed by one of the parents: "every thought, if he were here, would certainly be different. ..."

Therefore, it seems that in old age, along with living in the present and reviewing the past, which is characteristic of this stage in life, what defines the thoughts of the aging bereaved parents is a preoccupation with the "loss of the future." This same future that might have been, when one puts a positive spin to this lost future, becomes a kind of idealism that is related to the idealization of a deceased child. Thus, one perceives a kind of narrative running parallel to one's actual life story into which flow positive but unrealized thoughts about an ongoing and future relationship with the deceased.

Contrary to what Freud proposed (1917), it seems to us that parental bereavement does not involve decathexis from a deceased child. On the contrary, in addition to the physical separation from the child, an emotional process which can be called recathexis ensures that the relationship continues uninterrupted. This relationship is different from the previous emotional relationship because since it only exists in the parental internal world, it is accorded additional and unique qualities that did not exist in the past and are not present in the relationship with the living children.

Carstensen (1995) asserts that in aging we return to home base. There is an increasing need to reconnect with the people we care most about. In later life, we recenter our lives around our most gratifying core relationshipsspouse, children, grandchildren, and closest friends. This natural tendency to reconnect is probably also expressed in the older parents ' bereavement process and it thus adds to our understanding of their preoccupation with the deceased child.

In view of everything that has been said above, it seems to us that the bereaved parents' relationship to the personal death is unique and complex: it seems from the interviews that bereaved parents expressed a longing to reconnect with the deceased child, a wish that actually can only be realized with their own death, alongside a worry that with their demise, their child will die a second death.

On the one hand, therefore, the parents might feel a desire to merge with the deceased child, to rest. On the other hand, they feel that their death will also result in that of the child who lives within them, and this, in turn, leads to a fear of dying.

When summarizing the interviews with aged bereaved parents, one can see that over the years, two central features have arisen regarding the bereavement process:

1. Bereavement over the years is a dynamic process, developing and forming in a manner similar to other developmental processes throughout 
life. Even the parents' truncated lives are re-experienced and continue, likened to a story that has been written and rewritten, in an attempt to provide significance, an objective, an identity, order and a sense of belonging.

2. Grief can be expressed in a variety of ways which can range from one extreme to another, from a flood of emotions to restraint, from detachment to hyperactivity, from growing closer to isolation, etc. These expressions reflect the great differences between individuals, between families, and the past relationship with the deceased child experienced by each individual member of the family.

The significance of this study's findings as a contribution to the close environment and the treatment environment is the message or the lesson that we should accept and respect the differences between the mourners instead of trying to make their reactions "fit" an existing model or formula. The goal, therefore, is to help the family to construct a meaning and adopt a life style which will enable them to continue with their lives, in spite of the loss and pain that have become an integral part of their lives.

It should be pointed out that the findings of the present study are based upon a small sample which does not fully represent the variegated population of bereaved parents, and these procedures should be examined by a broader or more representative sampling. Despite the fact that the sample is small and the analysis is qualitative, making it more difficult to generalize the findings, it seems to us that in view of the complexity, sensitivity and pain of the loss which remain unflagging throughout the years, more in-depth personal interviews should be held in the same vein, ensuring that they are closely monitored and directed by the interviewers.

During the study, a very special and moving relationship left its mark on the interviewees as well as on the interviewers and the authors of the study. Much time was spent on discussions regarding the effects of the interviews on each of the study participants. This was expressed by a feeling of a personal brush with our own mortality and that of our dear ones, our own encounters with general and personal bereavement, with the fears, the great sadness, and identifying with the unbearable pain. In listening to the voices of the parents, we touched upon the very essence of the broken heart.

\section{REFERENCES}

Bowlby, J. (1980). Attachment and loss: Vol 3. Loss: Sadness and depression. Cambridge, England: Cambridge University Press. 
Carstensen, L. L. (1995). Evidence for a life-span theory of socioemotional selectivity. Current Directions of Psychological Science, 4, 253-258.

Carstensen, L. L., Levenson, R. W., \& Gottman, J. M. (1995). Emotional behavior in long-term marriage. Psychology and Aging, 10, 140-149.

Christ, G. H., Bonano, G. A., Malkinson, R., \& Rubin S. (2003). Bereavement experiences after the death of a child. In M. J. Field \& R. E. Behrman (Eds.), When children die: Improving palliative and end-of-life for children and their families (Appendix E, pp. 553-579). Institute of Medicine, Washington, DC: National Academy Press.

Cicirelli, V. G. (1995). Loss of siblings through death. In V. G. Cicirelli (Ed.), Sibling relationships across the life-span (Ch. 13, pp. 185-199). New York: Plenum Press.

Conway, V., \& Feeney, J. (1997). Attachments and grief: A study of parental bereavement. Journal of Family Studies, 3, 36-42.

Davis, B. (1999). Shadows in the sun: Experiences of sibling bereavement in childhood. Philadelphia, PA: Taylor and Francis.

DeFrain, J. (1991). Learning about grief from normal families: SIDS, stillbirths, and miscarriages. Journal of Marital and Family Therapy, 17, 215-223.

Diehl, M., Coyle, N., \& Labouvie-Vief, G. (1996). Age and sex differences in strategies of coping and defense across the life span. Psychology and Aging, 11(1), 127-139.

Edelstein, L. (1984). Mental bereavement. New York: Praeger.

Freud, Z. (1917). Trauer und Melancholie (Grief and melancholy). Teredional Zeritschrift fur Artztliche Psychoanalyse, 4, 288-301.

Kavanaugh, F. (1997). Gender differences among parents who experienced the death of an infant weighing less then 500 grams at birth. Omega, 35, 281-296.

Klass, D., Silverman, P. R., \& Nickman, S. L. (1996). Continuing bonds: New understandings of grief. Washington, DC: Taylor \& Francis.

Lang, A., \& Gottlieb, L. (1993). Marital intimacy after infant death. Death Studies, 17, 233-256.

Lesher, E. L., \& Berger, K. J. (1988). Bereaved elderly mothers: Changes in health, functional activities, family cohesion, and psychological well-being. International Journal of Aging \& Human Development, 26, 81-90.

Levav, I. (1989-1990). Second thoughts on the lethal aftermath of a loss. Omega, 20, 81-90.

Lomranz, J. (1998). An image of aging and the concept ofaintegration: Coping and mental health implications. In J. Lomranz (Ed.), Handbook of aging and mental health: An integrative approach. New York: Plenum Press.

Malkinson, R., \& Bar-Tur, L. (1999). The aging of grief in Israel: A perspective of bereaved parents. Death Studies, 23(6), 413-431.

Malkinson, R., \& Bar-Tur, L. (2000). The aging of grief: Parents' grieving of Israeli soldiers. Journal of Personal \& Interpersonal Loss, 5(2-3), 247-262.

Malkinson, R., Rubin, S., \& Witztum, E. (2005). Terror, trauma, and bereavement: Implications for theory and therapy. Journal of Aggression, Maltreatment \& Trauma, Special issue: The trauma of terrorism: Sharing knowledge and shared care, guest edited by Y. Danieli, D. Brom, \& J. Sills. 
Martin, T. L., \& Doka, K. J. (2000). Men don't cry . . . Women do. Pennsylvania: Brunner/Mazel.

Neidig, J. R., \& Dalgas-Pelish, P. (1991). Parental grieving and perceptions regarding health care professionals' intervention. Issues in Comprehensive Pediatric Nursing, 14, 179-191.

Neimeyer, R. A. (2001). The language of loss: Grief therapy as a process of meaning reconstruction. In R. A. Neimeyer (Ed.), Meaning reconstruction and the experience of loss (pp. 261-292). Washington, DC: American Psychological Association.

Neimeyer, R. A., Keese, N. J., \& Fortner, B. (2000). Loss and meaning reconstruction. In R. Malkinson, S. Rubin, \& E. Witztum (Eds.), Traumatic and nontraumatic loss and bereavement: Clinical theory and practice (pp. 173-196). Madison, CT: Psychosocial Press.

Patton, M. Q. (1980). Qualitative evaluation methods. Beverly Hills, CA: Sage.

Rando, T. A. (1983). An investigation of grief and adaptation in parents of children who have died from cancer. Journal of Pediatric Psychology, 8(1), 3-20.

Rando, T. A. (1993). Treatment of complicated grief. Champaign, Ill: Research Press.

Raphael, B. (1983). The anatomy of bereavement. New York: Basic Books.

Riches, G., \& Dawson, P. (1996). Communities of feelings. Mortality, 1(2), 143-162.

Riches, G., \& Dawson, P. (2000). An intimate loneliness: Supporting bereaved parents and sibling. Philadelphia: Open University Press

Rosen, H. (1985). Prohibitions against mourning in childhood sibling loss. Omega, 15, 307-316.

Rosenblatt, P. C. (2000). Parent grief: Narretives of loss and relationship. Philadelphia: Brunner/Mazel.

Rubin, S. (1990). Death of the future: An outcome study of bereaved parents in Israel. Omega, 20(4), 323-339.

Rubin, S. (1992). Adult child loss and the Two Track Model of Bereavement. Omega, 24(3), 183-202.

Rubin, S. (1999). The Two-Track Model of Bereavement: Overview, retrospect and retrospect. Death Studies, 23(8), 681-714.

Rubin, S. (2000). Psychodynamic perspectives on treatment with the bereaved: Modifications of the therapeutic/transference paradigm. In R. Malkinson, S. Rubin, \& E. Witztum (Eds.), Traumatic and nontraumatic loss and bereavement: Clinical theory and practice (pp. 117-141). Madison, CT: Psychosocial Press.

Rubin, S., \& Malkinson, R. (2001). Parental response to child loss across the life-cycle: Clinical and research perspectives. In M. Stroebe, R. Hansson, W. Stroebe, \& H. Schut (Eds.), Handbook of bereavement research: Consequences, coping and care (pp. 219-240). Washington, DC: American Psychological Association Press.

Rubin, S., Malkinson, R., \& Witztum, E. (2003). Trauma and bereavement: Conceptual and clinical issues revolving around relationships. Death Studies, 27, 1-27.

Schwab, R. (1996). Gender differences in parental grief. Death Studies, 20(2), 103-114.

Schwab, R. (1998). A child's death and divorce: Dispelling the myth. Death Studies, 22(5), 445-468. 
Valliant, G. E. (2002). Aging well. New York: Little, Brown and Company.

\author{
Direct reprint requests to: \\ Ruth Malkinson \\ The Bob Shapell School of Social Work \\ Tel Aviv University \\ POB 39040 \\ Ramat Aviv \\ Tel Aviv 69978 \\ Israel \\ e-mail: malkins@agri.huji.ac.il
}


Copyright of Omega: Journal of Death \& Dying is the property of Baywood Publishing Company, Inc. and its content may not be copied or emailed to multiple sites or posted to a listserv without the copyright holder's express written permission. However, users may print, download, or email articles for individual use. 